\title{
The Association Between Family Violence, Depression and Anxiety Among Women Whose Partners Have Been Treated for Alcohol Dependence
}

\author{
Natasa Dostanic ${ }^{1}$ (D) $\cdot$ Bosiljka Djikanovic $^{2} \cdot$ Mirjana Jovanovic $^{3} \cdot$ Zeljka Stamenkovic $^{2} \cdot$ Aleksandra Đeric $^{4}$
}

Accepted: 17 December 2020 / Published online: 2 January 2021

(C) The Author(s), under exclusive licence to Springer Science+Business Media, LLC part of Springer Nature 2021

\begin{abstract}
The negative effects of men's excessive alcohol consumption on family members are well known. However, less is known about how men's alcohol dependence is associated with the mental health of their female spouses residing with them. Therefore, the aim of this study was to investigate the prevalence and factors associated with depression, anxiety, and intimate partner violence against women (IPVAW) whose male spouses are undergoing treatment for alcohol dependence. We hypothesize that men with alcohol dependency, who are also violent, present a serious threat to women's mental health. We conducted a cross-sectional study among 104 women whose male partners had been admitted for inpatient treatment for alcohol dependence. Women's depression was measured by the Beck Depression Inventory (BDI-II); anxiety was measured by the Beck Anxiety Inventory (BAI), and exposure to physical and sexual IPVAW was measured by the Conflict Tactics Scale (CTS-2). Multinomial logistic regression analyses were conducted in order to analyze factors associated with depression and anxiety. The prevalence of moderate/severe depression and anxiety among the women was $34.6 \%$ and $25.2 \%$, respectively, while almost half $(48.1 \%)$ experienced IPV during the past 12 months. After adjustments for age, exposure to IPV increased the chances of experiencing moderate/severe depression by 37.5 times (95\% CI 7.91-177.76), and 8.15 times for moderate/severe anxiety (95\% CI 2.4527.14). The mental health of women whose partners have alcohol dependence is significantly threatened and should be considered, especially when it is associated with exposure to spousal violence.
\end{abstract}

Keywords Alcohol dependence $\cdot$ Alcohol use disorders (AUD) $\cdot$ Abuse $\cdot$ Violence $\cdot$ Women $\cdot$ Mental health $\cdot$ Anxiety · Depression

Excessive alcohol consumption may lead to alcohol dependence and the need for treatment. According to the World Health Organization [WHO] (2007), the incidence of alcoholism in the world is $3-5 \%$ of the adult population. The prevalence of alcohol dependence in the WHO European Region in 2016 was $3.7 \%$. In Serbia, a country located in South Eastern

Natasa Dostanic

nakidostanic@gmail.com

1 Special Hospital for Addictions, Department for Alcoholism, Teodora Drajzera 44, 11000 Belgrade, Serbia

2 Faculty of Medicine, Institute of Social Medicine, Centre - School of Public, University of Belgrade, Belgrade, Serbia

3 Faculty of Medical Sciences, Department of Psychiatry, University of Kragujevac, Kragujevac, Serbia

4 Clinic for Mental Disorders "Dr Laza Lazarevic", Belgrade, Serbia
Europe, but not part of the European Union, the prevalence is $3.4 \%$ (5,5\% men and $1.3 \%$ female), which is a little bit lower than EU average (World Health Organization 2018).

Serbia has experienced a very stressful living and working environment during the last 30 years, which were turbulent in terms of societal changes and transitions from socialism to a market-oriented economy (Nikolic-Ristanovic and Copic 2016). These societal changes also increased inequalities and poverty. Taking this into account, one might expect that the proportion of harmful alcohol consumption in the Serbian population is even higher than statistics indicate. In addition, many families in the countryside have a tradition of homeproducing alcohol beverages from plenty of available domestic fruits (usually plums), at almost no cost; however, there are no official statistical data about the scale of this production.

In general, the majority of alcohol dependent persons are men (5.4 vs. 1.5) (Peacock et al. 2018), who can be, at the 
same time, fathers and husbands. Men's alcohol consumption certainly affects the well-being of their family members, especially spouses (Orford et al. 2019). Many studies have investigated alcohol's harm on women who have alcoholdependent partners, and it was found that they more often complain about psychosomatic diseases (Dandu et al. 2017), poor mental health (Dandu et al. 2017; Dawson et al. 2007; Kishor et al. 2013), or becoming substance dependent themselves (Dawson et al. 2007; Greenfield et al. 2015; KarrikerJaffe and Greenfield 2014; Schuckit et al. 2002), in comparison to women whose partners are not alcohol dependent. Psychiatric morbidity is common among wives of alcoholdependent men. Two studies identified this type of morbidity in at least $63 \%$ of women (Bagul et al. 2015; Kishor et al. 2013).

Depression and anxiety are the most common psychiatric disorders among women whose partners have alcohol dependence (Kishor et al. 2013). Depression occurs three times and anxiety occurs two times more often in comparison to women whose husbands are not alcohol dependent (Ariyasinghe et al. 2015; Dandu et al. 2017; Kishor et al. 2013).

The mechanisms that lead to the development of depression and anxiety among women, whose partners are alcohol dependent, may be connected to alcohol-related contextual factors: heavy burden of stress due to partner's excessive drinking and inability to stop, usually followed by spousal quarrels and disputes, their unreliability and failure to be responsible family members and to care for others, uncritical spending money, and distorted priorities where alcohol consumption is the focus ( Huhtanen and Tigerstedt 2012; Kwon et al. 2015; Laslett et al. 2017; Schuckit et al. 2002; World Health Organization 2018). Prolonged living in such a stressful domestic environment caused by partners excessive alcohol drinking can lead to the weakening of women's capacity to achieve their well-being and optimal mental health.

Additional social factors that could explain and reinforce the harmful effects of alcohol consumption on women's anxiety and depression are numerous. Some studies indicated that these factors include lower social status and educational level, unemployment, number of children, living in rural areas, and difference in the education status of partners (Ariyasinghe et al. 2015; Dandu et al. 2017; Dawson et al. 2007; Karriker-Jaffe and Greenfield 2014; Karriker-Jaffe et al. 2017; Kishor et al. 2013; Schuckit et al. 2002; Seid et al. 2015; Nayak et al. 2019; Quigg et al. 2019).

Additionally, it is well known that harmful drinking facilitates the expression of aggressive and violent behavior. This is a partner-level risk factor of the well-known ecological model that explains intimate partner violence against women (IPVAW) (Abramsky et al. 2011; Capaldi et al. 2012; Djikanovic et al. 2010; Heise et al. 1999). Furthermore, exposure to violence increases the likelihood of psychiatric symptoms and morbidity in victims, especially depression and anxiety (Ariyasinghe et al. 2015; Bonomi et al. 2009; Dandu et al. 2017; Djikanovic et al. 2013; Golding 1999; Indu et al. 2018; Karakurt et al. 2014). After experiencing violence, women often feel guilty, repress their angriness, have low self-esteem, feel pessimistic, have no belief that something can change for the better in the future, and keep living in constant fear that the violence will be repeated, along with their partner's alcohol consumption (Golding 1999). If these symptoms persist over time and there is repeat violence, women become more and more sad and develop depression and / or anxiety over time, which influence their functioning in everyday life (Golding 1999).

Alcohol dependence requires treatment which might be long-lasting and which requires the commitment of all family members, especially spouses (Brooks et al. 2017; McCann et al. 2019). Intensive treatment of alcohol dependent men means changes in the patterns of addictive behaviors, and attitudes towards members of the family. In family/couplebased treatment programs, spouses can play an important role (McCann et al. 2019). Women can help to better support their husbands in the recovery process. Women's ability to participate in the process of treatment and rehabilitation might be affected by their own physical and mental health.

However, less is known about the mental health status of women who serve as a support system for their male partners being treated for alcohol dependence. They could be an important source of help, although they themselves might need help for physical and mental health problems if developed over time, especially when this coincides with intimate partner violence (McCann et al. 2017). According to the data from WHO-Multi Country study on violence against women that was conducted in Serbia, $39.8 \%$ of women whose partners are consuming alcohol almost every day have experienced physical or sexual violence (Djikanovic et al. 2010).

Preserving mental health is a challenge in Serbia given its turbulent past and current societal challenges. This may be particularly true in families with excessive alcohol consumption which has resulted in the need for inpatient treatment.

The research project described in this paper was conducted in an inpatient department for alcohol dependence, where patients are admitted for one-month medical and psychosocial treatment. During that time, their spouses (if available and willing) were invited to come to take a part in the psychosocial support program.

The aim of this study was to investigate the prevalence of mental health outcomes (depression and anxiety) among women whose spouses are under the treatment for alcohol dependence and factors associated with it. We hypothesized that the mental health of women who are living with alcoholdependent partners is also affected by exposure to intimate partner violence and the length of time they spent together in cohabitation / union. 


\section{Methods}

\section{Participants}

The research was designed as a cross-sectional study among female spouses of men who have been treated for alcohol dependence, according to the International Classification of Diseases-10 (ICD-10) of mental and behavioral disorders, at the Special Hospital for Addictions in Belgrade, Serbia. Participants were 104 female spouses of men who received inpatient treatment for alcohol dependence.

\section{Procedure}

The study was conducted from January to June 2018. All women who visited the department where their husbands were admitted for treatment were approached regarding study participation. If a woman was interested in participation, older than age 18, and was married or living in a civil partnership for a year or more, she was provided informed consent and completed a self-administered questionnaire. Out of 108 women, 4 women declined participation, stating that they did not have a time for it. The 104 women completed the questionnaire (response rate 96\%), expressed that they appreciated the opportunity to say something about themselves and their health, and perceived it as care for their own wellbeing, not just for their husbands. The study was approved by the hospital's ethics committee.

The self-administered questionnaire focused on current symptoms of depression, anxiety, alcohol use, and exposure to physical/sexual intimate partner violence. Demographic and socio-economic information about participants and her partner were also assessed.

\section{Measures}

\section{Socio-demographic Variables}

In this study we considered the following socio-demographic characteristics of both partners: age, level of education, working status; characteristics of the partnership (duration; number of children, place of living); the presence of some selfreported physical/psychiatric diseases among both women and their husbands, and the number of times a male partner underwent treatment for alcohol dependence.

\section{Depression}

We assessed depression using the Beck Depression Inventory (BDI-II). BDI-II holds a significant standing among depression assessment scales because of its reliability and validity (Beck and Beamesdorfer 1974). In our study, the internal consistency of BDI-II scale as measured by Cronbach alpha coefficient was
0.92 , which is very similar to other studies conducted worldwide (Wang and Gorenstein 2013). The scale has 21 questions about how the respondent had been feeling in the last week, with four options of answers, on a scale of 0 to 3 (for example 0 - "I do not feel sad, and 3- I am so sad and unhappy that I can't stand it). The total score on the scale is obtained by summing all the answers received from questions 1 to 21 , which leads to maximum score of 63 . The total score is compared to a key to determine the severity of depression. The standard cut-off points for categories are: $0-9$ points indicates no depression; 10-18 points indicates mild depression; 19-29 moderate depression; and 30-63 indicates severe depression (Beck and Beamesdorfer 1974). In our further data analysis, moderate and severe depression was combined (summed) to one variable called "moderately/severely depressed", which makes three comparison categories: no depression, mild depression, and moderately/severely depressed.

\section{Anxiety}

We measured anxiety by the commonly used Beck Anxiety Inventory (BAI), which has good psychometric characteristics (Beck et al. 1988). In our study, the internal consistency of BAI scale was very good $(\alpha=0.94)$, which replicates coefficients found in literature, in different populations (Magán et al. 2008). This instrument consists of 21 questions related to symptoms of general anxiety. Respondents answered each question by assessing the intensity of symptoms on a Likert scale from not present (0) to very much expressed (3). The total score of all responses (maximal $=63$ ) represents the intensity of symptoms of general anxiety. Cut-off points for categories of anxiety were the same as for depression. In our further data analysis, moderate and severe anxiety was combined (summed) to one variable called "moderate/severe anxiety", which makes three comparison categories: no anxiety, mild anxiety, and moderate/severe anxiety.

\section{Alcohol Consumption}

Women's use of alcohol was measured by the Alcohol Use Disorders Identification Test (AUDIT) (Babor et al. 2001). AUDIT is a screening test intended for the early identification of risky and harmful drinking as well as alcohol dependence in adult populations, and was developed and recommended by WHO (Babor et al. 2001). It consists of 10 questions pertaining to recent alcohol consumption, the existence of alcohol dependency symptoms, and problems associated with alcohol consumption. It complies with the ICD 10 definitions of alcohol dependence and harmful alcohol use. Answers are scored in the range of 0 to 4 , where 0 refers to "never" and 4 refers to "almost every day". The values of all the answers are summed to get a composite score. The minimum score (those who do not drink) is 0 and the maximum score is 40 . A score 
of 8 and above indicates a high likelihood of hazardous or harmful alcohol use (Babor et al. 2001). The higher the sum, the more likely it is for a respondent to be addicted to alcohol.

\section{Exposure to Physical/Sexual Intimate Partner Violence}

Exposure to male partner's violence was measured by the short form Conflict Tactics Scale (CTS 2) (Garcia-Moreno et al. 2006; Straus et al. 1996). This scale includes six behaviorally specific questions regarding exposure to physical violence, such as "Has your current partner/husband slapped you, or thrown something at you that could hurt you?", and three questions related to exposure to sexual violence, such as: "Were you ever physically forced to have sexual intercourse when you did not want to?". Women were asked about these experiences in their lifetime, and during the last 12 months. In this analysis, we used just the data on violence that occurred during the last 12 months. This scale showed very good psychometric and internal consistency measures in a representative, general population sample of women (Cronbach alpha value of 0.81), as validated in Serbia in a study conducted as part of the WHO multi-country study on women's health and domestic violence (Djikanovic et al. 2010). In the current study, this scale also performed very well, with a Cronbach alpha value of 0.72 .

\section{Statistical Analysis}

Mental health outcomes of women who are living with alcohol dependent partners and wide range of socio-demographic variables and experience with partner violence were tested by the chi square test. Variables, which results of the chi square test had a $p$ value of 0.05 and less, were included in univariate and adjusted multinomial logistic regression analysis. Results were presented as odds ratios (OR) with a 95\% confidence interval (CI). The level of significance was set at 0.05 and 0.01 .

\section{Results}

In our sample of 104 women whose spouses have been treated for alcoholism, more than half were younger than 50 years old $(53.4 \%)$, completed secondary education $(53.8 \%)$, and were employed (64.4\%). This information is displayed in the column named "total" in Table 1. More than half of women (56.3\%) have been in the partnership with their spouse between 11 and 20 years; the majority have at least 1 child (88.3\%), were living in urban area $(68.3 \%)$, and were of the same educational level as their partner $(68.3 \%)$. Almost three of four male spouses $(74.5 \%)$ were in treatment for the first time. Physical intimate partner violence was experienced by almost half of women (46.1\%), and $16.3 \%$ experienced sexual violence by their current partner who is in alcohol treatment.
Almost all women who experienced sexual violence, were exposed to physical violence as well (15 out of 17 , or $88.2 \%)$. The proportion of women who experienced either physical or sexual violence was $48.1 \%$, and this group was used for further analyses of associations between mental health outcomes and exposure to IPV (Table 1). Harmful alcohol consumption had not been reported by women in this sample, since $100 \%$ of women had a score lower than 8 .

\section{Depression and Anxiety}

Two of three women in this sample were either mildly (37 or $33.5 \%$ ) or moderately/severely depressed (36 or $34.6 \%$ ), while $29.8 \%$ ( 31 women) had a score that is within the normal cut-off points, indicating no depression. Among mildly and moderately/severely depressed women there were significantly more women older than 50 years $(p=0.024)$, whose partner was also older than $50(p=0.024)$, and they were more often at least 20 years in the union with their partner who has been under the treatment for alcohol addiction $(p=0.007)$ (Table 1). Depression was also more frequent among women who reported the presence of some physical illness $(p=$ 0.036 ). When the experience of intimate partner violence in the last 12 months is concerned, there were statistically highly significant differences for all combinations of exposure to physical and/or sexual violence and depression (Table 1).

Every fourth women in our sample $(25.2 \%)$ had moderate or severe anxiety. Mild anxiety was found in $30.1 \%$ of the women, and no anxiety was found in $44.7 \%$ of the women. Differences in the state of anxiety in women of different age group was not significant ( $p=0.173$ ), although it was observed that more anxiety was present among women whose partner was older than 50. Differences in the frequency of moderate or severe anxiety and the wide range of variables are presented in Table 2 . It is fairly similar to the pattern observed for depression, although additional variables such as place of living, presence of physical diseases in women, and the number of partner's treatments for alcohol addiction appeared to be significant.

\section{The Impact of Intimate Partner Violence and the Length of Partnership on Depression and Anxiety}

Multinomial logistic regression model was conducted to test meaningful associations between depression and anxiety as outcomes, and some explanatory variables (intimate partner violence, duration of union) which demonstrated statistically significant difference in frequency of distribution (Tables 3 and 4). Women's age (being 50 years or older) increased women's chances to be either mildly (OR 7.31, 95\% CI 1.44-37.16) or moderately/severely depressed (OR 9.00, 
Table 1 Depression and demographic and health characteristics of women and their partnership with man who is under the treatment for alcohol consumption

\begin{tabular}{|c|c|c|c|c|c|c|c|c|c|}
\hline & \multicolumn{2}{|c|}{$\begin{array}{l}\text { No depression } \\
n=31 \\
29.8 \%\end{array}$} & \multirow{2}{*}{$\begin{array}{l}\text { Mild depression } \\
n=37 \\
35.5 \% \\
N\end{array}$} & \multirow[b]{2}{*}{$\%$} & \multirow{2}{*}{$\begin{array}{l}\text { Moderately/ } \\
\text { severely depressed } \\
n=36 \\
34.6 \% \\
N\end{array}$} & \multirow[b]{2}{*}{$\%$} & \multicolumn{2}{|l|}{ Total } & \multirow[t]{2}{*}{$\begin{array}{l}\chi^{2} \text { value } \\
p \text { value }\end{array}$} \\
\hline & $N$ & $\%$ & & & & & $N$ & $\%$ & \\
\hline \multicolumn{10}{|l|}{ Women's age } \\
\hline Up to 39 years old & 9 & 52.9 & 4 & 23.5 & 4 & 23.5 & 17 & 16.5 & \multirow{4}{*}{$\begin{array}{l}\chi^{2}=14.52 \\
0.024\end{array}$} \\
\hline $40-49$ years old & 16 & 42.1 & 12 & 31.6 & 10 & 26.3 & 38 & 36.9 & \\
\hline $50-59$ years old & 4 & 12.1 & 13 & 39.4 & 16 & 48.5 & 33 & 32.0 & \\
\hline 60 years old and more & 2 & 13.3 & 7 & 46.6 & 6 & 40.0 & 15 & 14.6 & \\
\hline \multicolumn{10}{|l|}{ Women's education } \\
\hline Primary school & 1 & 16.7 & 3 & 50.0 & 2 & 33.3 & 6 & 5.8 & \multirow{3}{*}{$\begin{array}{l}\chi^{2}=1.24 \\
0.871\end{array}$} \\
\hline High school & 16 & 28.6 & 19 & 33.9 & 21 & 37.5 & 56 & 53.8 & \\
\hline Higher education & 14 & 33.3 & 15 & 35.7 & 13 & 31.0 & 42 & 40.4 & \\
\hline \multicolumn{10}{|l|}{ Women's working status } \\
\hline Employed & 22 & 32.8 & 20 & 29.9 & 25 & 37.3 & 67 & 64.4 & \multirow{3}{*}{$\begin{array}{l}\chi^{2}=8.60 \\
0.072\end{array}$} \\
\hline Unemployed & 9 & 34.6 & 12 & 46.2 & 5 & 19.2 & 26 & 25.5 & \\
\hline Retired & - & - & 5 & 45.5 & 6 & 54.5 & 11 & 10.6 & \\
\hline \multicolumn{10}{|l|}{ Partner's age } \\
\hline Up to 39 years old & 8 & 57.1 & 4 & 28.6 & 2 & 14.3 & 14 & 13.7 & \multirow{4}{*}{$\begin{array}{l}\chi^{2}=18.83 \\
0.004\end{array}$} \\
\hline $40-49$ years old & 16 & 45.7 & 10 & 28.6 & 9 & 25.7 & 35 & 34.3 & \\
\hline $50-59$ years old & 7 & 18.4 & 12 & 31.6 & 19 & 50.0 & 38 & 37.2 & \\
\hline 60 years old and more & - & - & 7 & 53.8 & 6 & 46.2 & 13 & 12.7 & \\
\hline \multicolumn{10}{|l|}{ Partner's education } \\
\hline Primary school & 2 & 22.2 & 6 & 66.7 & 1 & 11.1 & 9 & 8.7 & \multirow{3}{*}{$\begin{array}{l}\chi^{2}=4.51 \\
0.341\end{array}$} \\
\hline High school & 19 & 29.7 & 21 & 32.8 & 24 & 37.5 & 64 & 61.5 & \\
\hline Higher education & 10 & 32.3 & 10 & 32.3 & 11 & 35.5 & 31 & 29.8 & \\
\hline \multicolumn{10}{|l|}{ Partner's working status } \\
\hline Employed & 21 & 30.4 & 23 & 33.3 & 25 & 36.2 & 69 & 63.3 & \multirow{3}{*}{$\begin{array}{l}\chi^{2}=5.20 \\
0.267\end{array}$} \\
\hline Unemployed & 10 & 38.5 & 9 & 34.6 & 7 & 26.9 & 26 & 25.0 & \\
\hline Retired & - & - & 5 & 55.6 & 4 & 44.4 & 9 & 8.7 & \\
\hline \multicolumn{10}{|l|}{ Duration of union / partnership } \\
\hline Up to 10 years & 11 & 52.4 & 8 & 38.1 & 2 & 9.5 & 21 & 20.4 & $\chi^{2}=17.84$ \\
\hline $11-20$ years & 13 & 35.1 & 12 & 32.4 & 12 & 32.4 & 37 & 56.3 & 0.007 \\
\hline $21-30$ years & 6 & 23.1 & 8 & 30.8 & 12 & 46.2 & 26 & 25.2 & \\
\hline 31 year and more & - & - & 9 & 47.4 & 10 & 52.6 & 19 & 18.4 & \\
\hline Number of children & & & & & & & & & \\
\hline 0 & 3 & 25.0 & 6 & 50.0 & 3 & 25.0 & 12 & 11.7 & $\chi^{2}=6.48$ \\
\hline 1 & 14 & 45.2 & 9 & 29.0 & 8 & 25.8 & 31 & 30.1 & 0.371 \\
\hline 2 & 13 & 24.1 & 19 & 35.2 & 22 & 40.7 & 54 & 52.4 & \\
\hline 3 and more & 1 & 16.7 & 3 & 50.0 & 2 & 33.3 & 6 & 11.7 & \\
\hline Place of living & & & & & & & & & \\
\hline City & 22 & 31.0 & 26 & 36.6 & 23 & 32.4 & 71 & 68.3 & $\chi^{2}=0.49$ \\
\hline Else & 9 & 27.3 & 11 & 33.3 & 13 & 39.4 & 33 & 31.7 & 0.782 \\
\hline Differences in the level of edu & ion a & spous & & & & & & & \\
\hline The same level of education & 16 & 24.6 & 22 & 33.8 & 27 & 41.5 & 65 & 63.7 & $\chi^{2}=5.60$ \\
\hline Man is more educated & 5 & 38.5 & 4 & 30.8 & 4 & 30.8 & 13 & 12.7 & 0.231 \\
\hline Woman is more educated & 10 & 41.7 & 10 & 41.7 & 4 & 16.7 & 24 & 23.5 & \\
\hline Presence of some physical dise & e in $v$ & & & & & & & & \\
\hline Yes & - & - & 4 & 36.4 & 7 & 63.6 & 11 & 11.4 & $x^{2}=6.66$ \\
\hline No & 31 & 33.3 & 33 & 35.5 & 29 & 31.2 & 93 & 88.6 & 0.036 \\
\hline
\end{tabular}


Table 1 (continued)

\begin{tabular}{|c|c|}
\hline $\begin{array}{l}\text { No depression } \\
n=31 \\
29.8 \%\end{array}$ & $\begin{array}{l}\text { Mild depressior } \\
n=37 \\
35.5 \%\end{array}$ \\
\hline$\%$ & $N$ \\
\hline
\end{tabular}

Moderately/
severely depressed
$n=36$
$34.6 \%$
$N$

$\% \quad N$

Presence of some psychiatric disease in women

Yes

No

$\begin{array}{ll}- & - \\ 31 & 30.1\end{array}$

1

Presence of some physical disease in partner

Yes

$6 \quad 31.6$

No

$25 \quad 29.4$

31.6
29.4

5

Presence of some psychiatric disease in partner

$\begin{array}{llll}\text { Yes } & - & - & 1\end{array}$

No

$31 \quad 30.4 \quad 36$

The number of treatments for alcohol addiction

$\begin{array}{llll}\text { The first treatment } & 24 & 33.3 & 25\end{array}$

$\begin{array}{llll}\text { Second treatment or more } & 6 & 19.4 & 12\end{array}$

Physical intimate partner violence in the last 12 months

$\begin{array}{llll}\text { Yes } & 4 & 8.3 & 16 \\ \text { No } & 27 & 48.2 & 21\end{array}$

Sexual intimate partner violence in the last 12 months

$\begin{array}{llll}\text { Yes } & 1 & 5.9 & 5\end{array}$

\begin{tabular}{|c|c|}
\hline No & \\
\hline
\end{tabular}

Physical OR sexual intimate partner violence in the last 12 months

$\begin{array}{llll}\text { Yes } & 4 & 8.0 & 17\end{array}$

$\begin{array}{llll}\text { No } & 27 & 50.0 & 20\end{array}$

Physical AND sexual intimate partner violence in the last 12 months

\begin{tabular}{lllllllll} 
Yes & 1 & 6.7 & 4 & 26.7 & 10 & 66.7 & 15 & 14.4 \\
No & 30 & 33.7 & 33 & 37.1 & 26 & $\chi^{2}=8.74$ \\
& & & & & 29.2 & 89 & 85.6 & 0.013 \\
\hline
\end{tabular}

95\% CI 1.80-44.96) (Table 3). Similar associations, although less strong, were found for partner's age (if the partner was 50-59 years old, chances for women's moderate/severe depression were 10.86 times higher, 95\% CI 1.86-64.08), and the length of the partnership: if they were together for 21 to 30 , chances for depression were much higher $(\mathrm{OR}=11.00,95 \%$ CI $1.82-66.34$ ) (Table 3). Due to the possible collinearity between timely bounded association, just women's age was used to control for the association between exposure to intimate partner violence, which proved to increase chances for mild depression by five times (OR 5.74, 95\%CI 1.67-19.69), and moderate/severe depression by more than 27 times (OR 27.96, 95\% CI 7.35-106.33). After controlling for women's age, the associations between exposure to violence and mild and moderate/severe depression proved to be even more significant (OR 7.79, 95\% CI 1.83-33.12, and OR 37.50, 95\%CI 7.91-177.76) (Table 3).

The multinomial logistic regression model that tested associations with mild/moderate and severe anxiety revealed that women who experienced IPV and who had some physical diseases had much higher chances to report anxiety, even after adjusting for women's age (Table 4).

\section{Discussion}

The main findings from our study that was conducted among women whose male partners were undergoing treatment for alcohol dependence indicated that women's mental health is affected by a number of factors, especially duration of the union and exposure to IPVAW.

Women's mental health status showed interesting results: we found that $70.2 \%$ of women experienced either mild or moderate/severe depression, while mild or moderate/severe anxiety was found in $55.3 \%$ of women, as measured by Back Inventory scales. We found the frequency of depression to be higher than what has been found in the majority of other studies conducted in other environments, although they used different measurement tools. For example, Bagul et al. (2015), in a smaller sample size $(N=67)$ found that in India the prevalence of depressive disorders among female respondents was $35 \%$, and anxiety disorders was $35 \%$. They used the General Health Questionnaire (GHO) to detect presence of psychiatric illness, where probable cases as identified by GHO were further assessed for the presence of the specific psychiatric disorder. In our study, it was not feasible to conduct further 
Table 2 Anxiety and demographic and health characteristics of women and their partnership with men who is under the treatment for alcohol consumption

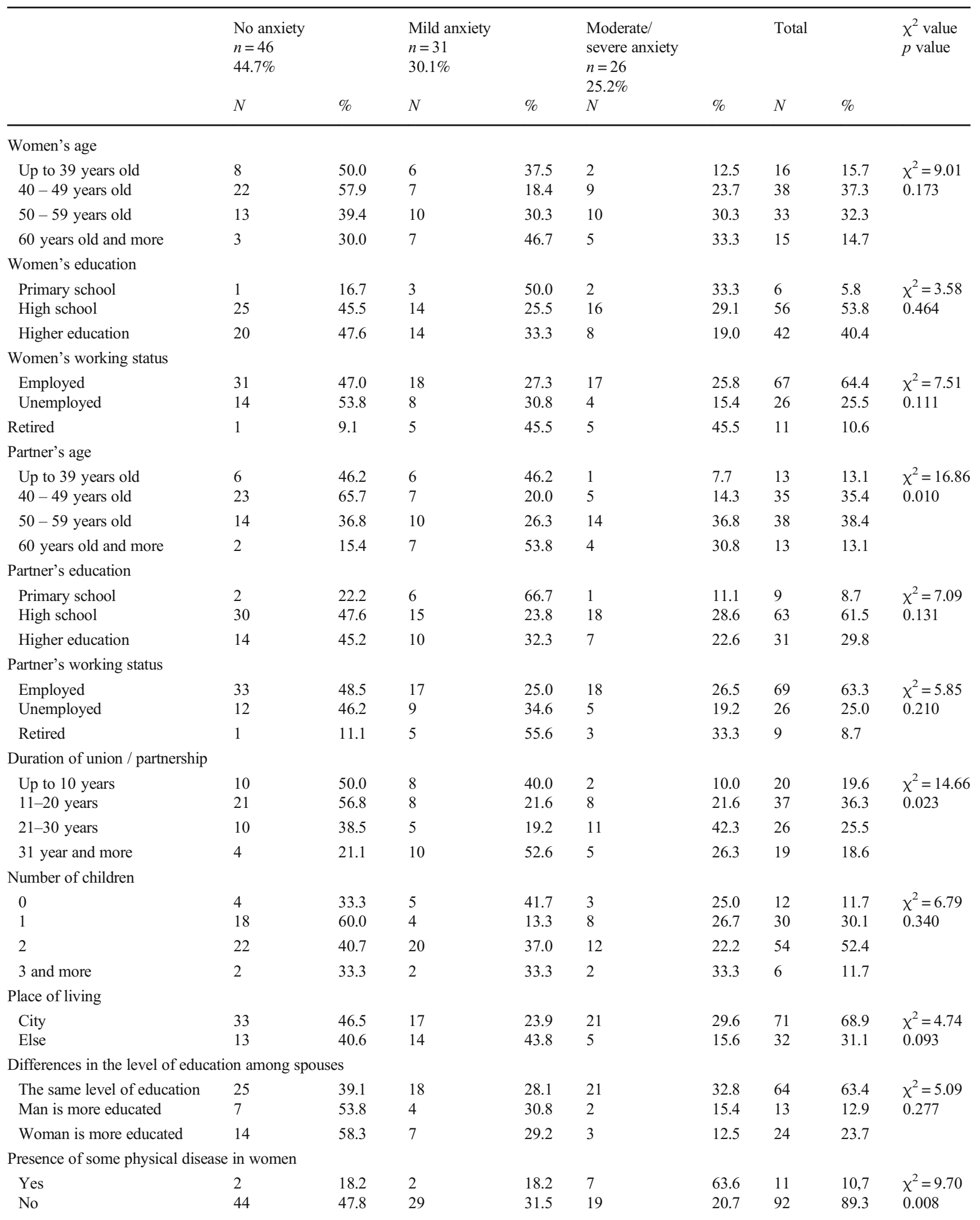


Table 2 (continued)

\begin{tabular}{|c|c|c|c|c|c|c|c|c|c|}
\hline & $\begin{array}{l}\text { No anxiety } \\
n=46 \\
44.7 \% \\
N\end{array}$ & $\%$ & $\begin{array}{l}\text { Mild anxiety } \\
n=31 \\
30.1 \% \\
N\end{array}$ & $\%$ & $\begin{array}{l}\text { Moderate/ } \\
\text { severe anxiety } \\
n=26 \\
25.2 \% \\
N\end{array}$ & $\%$ & Total & $\%$ & $\begin{array}{l}\chi^{2} \text { value } \\
p \text { value }\end{array}$ \\
\hline \multicolumn{10}{|c|}{ Presence of some psychiatric disease in women } \\
\hline $\begin{array}{l}\text { Yes } \\
\text { No }\end{array}$ & $\begin{array}{l}1 \\
45\end{array}$ & $\begin{array}{l}100.0 \\
44.1\end{array}$ & - & $\begin{array}{l}- \\
30.4\end{array}$ & - & $-\overline{25.5}$ & $\begin{array}{l}1 \\
102\end{array}$ & $\begin{array}{l}0.9 \\
99.1\end{array}$ & $\begin{array}{l}\chi^{2}=1.21 \\
0.535\end{array}$ \\
\hline \multicolumn{10}{|c|}{ Presence of some physical disease in partner } \\
\hline $\begin{array}{l}\text { Yes } \\
\text { No }\end{array}$ & $\begin{array}{l}7 \\
39\end{array}$ & $\begin{array}{l}36.8 \\
46.4\end{array}$ & $\begin{array}{l}7 \\
24\end{array}$ & $\begin{array}{l}36.8 \\
28.6\end{array}$ & $\begin{array}{l}5 \\
21\end{array}$ & $\begin{array}{l}26.3 \\
25.0\end{array}$ & $\begin{array}{l}19 \\
84\end{array}$ & $\begin{array}{l}18.5 \\
81.5\end{array}$ & $\begin{array}{l}\chi^{2}=0.68 \\
0.711\end{array}$ \\
\hline \multicolumn{10}{|c|}{ Presence of some psychiatric disease in partner } \\
\hline $\begin{array}{l}\text { Yes } \\
\text { No }\end{array}$ & $\begin{array}{l}2 \\
44\end{array}$ & $\begin{array}{l}100.0 \\
43.6\end{array}$ & - & $\begin{array}{l}- \\
30.7\end{array}$ & $\frac{-}{26}$ & $-\overline{25.7}$ & $\begin{array}{l}2 \\
101\end{array}$ & $\begin{array}{l}1.9 \\
98.1\end{array}$ & $\begin{array}{l}\chi^{2}=2.52 \\
0.283\end{array}$ \\
\hline \multicolumn{10}{|c|}{ The number of treatments for alcohol addiction } \\
\hline $\begin{array}{l}\text { The first treatment } \\
\text { Second treatment or more }\end{array}$ & $\begin{array}{l}37 \\
9\end{array}$ & $\begin{array}{l}52.1 \\
29.0\end{array}$ & $\begin{array}{l}19 \\
11\end{array}$ & $\begin{array}{l}26.8 \\
35.5\end{array}$ & $\begin{array}{l}15 \\
11\end{array}$ & $\begin{array}{l}26.1 \\
35.5\end{array}$ & $\begin{array}{l}71 \\
31\end{array}$ & $\begin{array}{l}69.6 \\
30.4\end{array}$ & $\begin{array}{l}\chi^{2}=4.85 \\
0.088\end{array}$ \\
\hline \multicolumn{10}{|c|}{ Physical OR sexual intimate partner violence in the last 12 months } \\
\hline $\begin{array}{l}\text { Yes } \\
\text { No }\end{array}$ & $\begin{array}{l}12 \\
34\end{array}$ & $\begin{array}{l}24.5 \\
63.0\end{array}$ & $\begin{array}{l}18 \\
13\end{array}$ & $\begin{array}{l}36.7 \\
24.1\end{array}$ & $\begin{array}{l}19 \\
7\end{array}$ & $\begin{array}{l}38.8 \\
13.0\end{array}$ & $\begin{array}{l}49 \\
54\end{array}$ & $\begin{array}{l}47.6 \\
52.4\end{array}$ & $\begin{array}{l}\chi^{2}=16.63 \\
<0.001\end{array}$ \\
\hline
\end{tabular}

assessment for psychiatric disorders (for example, using Structured Clinical Interview for DSM IV AXIS I disorder) since ethical postulates would require adequate clinical follow-up for positive cases. This was beyond our current research plans, although it remains to be considered as an option in future research, and also practice.

Dandu et al. (2017) had a research sample size similar to what we had (101 participants), and they found that $44.6 \%$ of women met the criteria for depressive disorder. These differences in the prevalence of depression and anxiety among women whose partners are alcohol dependent in different cultures could be ascribed to various factors. However, it is even more important to compare them with the prevalence of depression and anxiety in the general population. Results from the National Health Survey 2013 in Serbia indicated that just $5.3 \%$ of adult women had depression (as measured by the 8item Patient Health Questionnaire), whereas data on anxiety were not measured in that survey (Ilic 2014). This comparison clearly indicates that the frequency of depression is more than 13 times higher among women whose husbands are alcohol dependent, while other authors found that depression is "just" three times more often among them, in comparison to the women in the general population (Ariyasinghe et al. 2015; Dandu et al. 2017; Kishor et al. 2013).

Although our cross-sectional research design does not allow us to draw conclusions about causal relationships between mental health outcomes and life experiences (i.e. family atmosphere), we can reasonably state that women's depression and anxiety are developed over time as a consequence of living with an alcohol-dependent male partner. This is corroborated by our finding that women from longer partnerships/unions (more than 21 years) suffer from moderate/severe depression significantly more often than women in shorter partnerships ( $p=0.007)$. Knowing the context of Serbia and the theoretical framework presented in our Introduction, we would expect that depression and anxiety that is associated with the alcohol dependence of a male partner to be higher among women whose educational level is lower, who are unemployed, who have a higher number of children or who are living in rural areas (Ariyasinghe et al. 2015; Dandu et al. 2017; Dawson et al. 2007; Karriker-Jaffe and Greenfield 2014; KarrikerJaffe et al. 2017; Kishor et al. 2013; Nayak et al. 2019; Schuckit et al. 2002; Seid et al. 2015; Quigg et al. 2019). However, none of these expectations were confirmed by our findings. This may be ascribed to the relatively small study sample, which could not capture statistical significances. Duration of partnership was also significantly associated with depression, especially with moderate/severe depression (OR $11.00,95 \%$ CI $1.82-66.34)$, which confirms our literaturebased hypothesis that prolonged stress due to the partner's alcohol consumption has more severe and detrimental effects on women's mental health (Schuckit et al. 2002).

The other most important single predictor of women's poor mental health outcomes was exposure to violence perpetrated by their alcohol-dependent partners within the last 12 months, which increased chances for mild depression by more than five times (OR 5.74, 95\%CI $1.67-19.69$ ), and by 22 times for moderate/severe depression (OR 27.96, 95\%CI 7.35 106.33). These figures were even higher after adjusting for women's age. Similar results have been observed in predicting 
Table 3 Women's depression and factors associated with it: univariate and age-adjusted multinomial logistic regression model

Univariate model

Mild depression

OR $95 \%$ CI
Moderately/ severely depressed OR $95 \%$ CI
Age-adjusted model

Mild depression Moderately/ severely depressed OR $95 \%$ CI
OR $95 \%$ CI

\begin{tabular}{|c|c|c|c|c|}
\hline \multicolumn{5}{|l|}{ Women's age } \\
\hline Up to 39 years old & 1.00 & 1.00 & 1.00 & 1.00 \\
\hline $40-49$ years old & $1.690 .42-6.81$ & $1.410 .34-5.81$ & $3.320 .64-17.27$ & $4.640 .72-29.97$ \\
\hline $50-59$ years old & $7.31 * 1.44-37.16$ & $9.00 * * 1.80-44.96$ & $11.58 * * 1.84-73.04$ & $18.83 * * 2.50-142.00$ \\
\hline 60 years and more & $7.87 * 1.10-56.12$ & $6.750 .92-49.23$ & $11.79 * 1.35-103.20$ & $12.74 * 1.15-140.66$ \\
\hline \multicolumn{5}{|l|}{ Partner's age } \\
\hline Up to 39 years old & 1.00 & 1.00 & & \\
\hline $40-49$ years old & $1.250 .30-5.26$ & $2.250 .39-12.97$ & & \\
\hline $50-59$ years old & $3.430 .75-15.67$ & $10.86 * * 1.84-64.08$ & & \\
\hline 60 years and more & - & - & & \\
\hline \multicolumn{5}{|c|}{ Duration of partnership } \\
\hline Up to 10 years & 1.00 & 1.00 & & \\
\hline $11-20$ years & $1.270 .38-4.22$ & $5.080 .93-27.75$ & & \\
\hline $21-30$ years & $1.830 .45-7.41$ & $11.00 * * 1.82-66.34$ & & \\
\hline 31 year and more & - & - & & \\
\hline \multicolumn{5}{|c|}{ Physical OR sexual intimate partner violence in the last 12 months } \\
\hline No & 1.00 & 1.00 & 1.00 & 1.00 \\
\hline Yes & $5.74 * * 1.67-19.69$ & $27.96 * 7.35-106.33$ & $7.79 * * 1.83-33.12$ & $37.50 * * 7.91-177.76$ \\
\hline
\end{tabular}

${ }^{*} p<0.05 * * p<0.01$

moderate/severe anxiety, where intimate partner violence increased chances for it by three time (OR 3.01, 95\%CI $1.04-$ 8.75 ), and the presence of some physical disease increased it even more (OR 8.01, 95\%CI 1.54 - 42.67). In the adjusted model, odds ratios remained almost the same, which means that these two variables (exposure to violence and women's physical disease) independently increase the risk for women's anxiety. This finding emphasizes the relationship between women's physical and mental health, particularly anxiety, but also depression, which could not be modeled since all women with physical diseases experienced either mild $(36.4 \%)$ or moderate/severe depression $(63.6 \%)$, and none had "no depression".

Our findings confirmed our initial hypothesis that the male partner's harmful drinking plays an important role in violence against women, being one of the risk factors for IPV that appears at the partner-level of the ecological model (Abramsky et al. 2011; Djikanovic et al. 2010;). We found that almost half of women (48.1\%), whose partners are in treatment for alcohol consumption, experienced physical/ sexual intimate partner violence from them during the last 12 months. This proportion is more than 20 times higher than in the general Serbian population (2.3\%), as found in WHO Multi-country study (Garcia-Moreno et al. 2006). Our results are still lower in comparison to the study of Indu et al. (2018) who found that the incidence of IPVAW among spouses of alcohol-dependent men was up to $68.3 \%$. In comparison to the other addictions, such as pathological gambling, the incidence of IPVAW is much higher (Roberts et al. 2020).

These findings related to IPVAW perpetuated by alcoholdependent partners have to be interpreted within the wider context of individual, community and societal factors that facilitate expression of violence, and eventually negatively affects women's health. This has been found in previous studies as well (Abramsky et al. 2011; Karakurt et al. 2014). The fact that almost half of alcohol-dependent men who are undergoing inpatient treatment recently perpetuated IPVAW (during the last 12 months) presents a unique opportunity to address this issue during their treatment, and to emphasize zero tolerance to violence.

This study has certain limitations as well. They mainly relate to the cross-sectional study design, which does not allow establishing causal relationships between outcomes and possible predictors, as already mentioned. Due to the relatively small sample size $(n=104)$, the impact of variables that appear with low frequency were difficult to achieve statistical significance. On the other hand, we do not know anything about women whose husbands/partners are also undergoing treatment for alcohol dependence, but who do not appear at the department. That is, we do not know how (un)healthy and resilient they are; what is the level of their involvement with their partner/husbands who have alcohol dependence, and 
Table 4 Women's anxiety and factors associated with it: univariate and age-adjusted multinomial logistic regression model

Univariate model

\begin{tabular}{ll}
\hline Mild anxiety & Moderate/severe anxiety \\
OR 95\% CI & OR 95\% CI
\end{tabular}

Age-adjusted model

\begin{tabular}{ll}
\hline Mild anxiety & Moderate/severe anxiety \\
OR $95 \%$ CI & OR $95 \%$ CI
\end{tabular}

\begin{tabular}{|c|c|c|c|c|}
\hline \multicolumn{5}{|l|}{ Women's age } \\
\hline Up to 39 years old & 1.00 & 1.00 & & \\
\hline $40-49$ years old & $0.420 .11-1.65$ & $1.640 .29-9.25$ & & \\
\hline $50-59$ years old & $1.030 .27-3.92$ & $3.080 .53-17.80$ & & \\
\hline 60 years and more & $3.110 .56-17.33$ & $6.670 .81-54.96$ & & \\
\hline \multicolumn{5}{|l|}{ Partner's age } \\
\hline Up to 39 years old & 1.00 & 1.00 & & \\
\hline $40-49$ years old & $0.300 .07-1.25$ & $1.300 .13-13.37$ & & \\
\hline $50-59$ years old & $0.710 .18-2.87$ & $6.000 .64-56.52$ & & \\
\hline 60 years and more & $3.500 .50-24.27$ & $12.000 .80-180.97$ & & \\
\hline \multicolumn{5}{|l|}{ Duration of partnership } \\
\hline Up to 10 years & 1.00 & 1.00 & & \\
\hline $11-20$ years & $0.480 .14-1.64$ & $1.900 .34-10.67$ & & \\
\hline $21-30$ years & $0.620 .15-2.59$ & $5.500 .96-31.43$ & & \\
\hline 31 year and more & $3.120 .71-13.81$ & $6.250 .84-46.57$ & & \\
\hline \multicolumn{5}{|c|}{ Presence of some physical disease in women } \\
\hline Yes & 1.00 & 1.00 & 1.00 & 1.00 \\
\hline No & $1.520 .20-11.38$ & $8.10 * 1.54-42.67$ & $1.270 .13-12.28$ & $8.29 * 1.06-65.15$ \\
\hline \multicolumn{5}{|c|}{ Physical OR sexual intimate partner violence in the last 12 months } \\
\hline No & 1.00 & 1.00 & 1.00 & 1.00 \\
\hline Yes & $3.92 * * 1.49-10.35$ & $7.69 * * 2.59-22.83$ & $4.26 * * 1.47-12.34$ & $8.15 * 2.45-27.14$ \\
\hline
\end{tabular}

${ }^{*} p<0.05, * * p<0.01$

what their experiences are with partner violence. It is difficult to even speculate about it, especially in comparison to the women who are involved in their partner's treatment and rehabilitation during hospitalization.

The results of this study have a number of practical implications. Professionals, who are working with alcohol dependent men and their affected family members (i.e. most often their spouses), have to be aware that the health status of women who are supporting their partners during the treatment process could also be seriously affected. Our results indicated that women themselves might also need help and support; however, we do not know anything about their help-seeking behaviors or copying strategies in relation to their mental health outcomes. Their presence in the inpatient healthcare facility where their husbands are treated could be an opportunity to assess their own well-being, and to provide an initial professional response according to identified health needs.

Since the most important single risk factor for women's mental health is experiencing physical/sexual intimate partner violence, it is worthwhile to pay attention to it and perhaps to conduct screening on partner violence, but only by educated and confidential health professionals who are familiar with best practices and procedures that would follow women's confirmation of experience with violence. Addressing intimate partner violence is a complex skill and professionals might have different levels of readiness and preparedness to deal with it (Djikanovic et al. 2015), especially at the tertiary level of healthcare in Serbia, which has yet to be assessed. Additionally, overall societal measures should be in place to effectively protect women from violence, using a multisectoral approach, especially in situations such as the current COVID-19 pandemic which requires extended stay-at home measures. That atmosphere might trigger an increased alcohol consumption among men, with rising tensions that are leading to the use of violence, which has been already reported, based on an average one-third increase in calls to help lines (UN Women 2020).

Our study results also indicate that women's risk for poor mental health outcomes increases with women's age, which coincides with the duration of union with an alcohol dependent partner. It seems that a woman's resilience after the age of 50 is seriously jeopardized by both the deficit of female hormones which have a protective role, and living in adverse family circumstances with an alcohol dependent and violent 
partner. Some evidences suggest that social support to women can mitigate these effects (Costa and Gomes 2018), but it might depend on the empathy and gender norms in a certain society. Future studies and public health concerns should focus more on women in this age group and their health and social needs, especially taking into account that their proportion in the general population will be greater due to negative demographic trends and aging of the population.

Acknowledgements This work was supported by the Ministry of Science and Technological Development of Serbia (Project No 175025 and Project No 175042). Authors are very grateful to Dr Elizabeth King who kindly performed English language editing.

\section{References}

Abramsky, T., Watts, C. H., Garcia-Moreno, C., Devries, K., Kiss, L., Ellsberg, M., et al. (2011). What factors are associated with recent intimate partner violence? findings from the WHO multi-country study on women's health and domestic violence. BMC Public Health, 11, 109. https://doi.org/10.1186/1471-2458-11-109.

Ariyasinghe, D., Abeysinghe, R., Siriwardhana, P., \& Dassanayake, T. (2015). Prevalence of major depressive disorder among spouses of men who use alcohol in a rural community in Central Sri Lanka. Alcohol and Alcoholism, 50(3), 328-332. https://doi.org/10.1093/ alcalc/agu105.

Babor, T. F., Biddle-Higgins, J. C., Saunders, J. B., \& Monteiro, M. G. (2001). AUDIT: The alcohol use identification test: Guidelines for use in primary health care. Geneva: World Health Organization.

Bagul, K. R., Deshmukh, S. B., Bagul, M. K., \& Deshmukh, P. S. (2015). Psychiatric morbidity and marital quality among wives of patients with alcohol dependence syndrome. Journal of Evidence Based Medicine and Healthcare, 2(22), 3284-3295. (eISSN 2349-2570).

Beck, A. T., \& Beamesdorfer, A. (1974). Assessment of depression: the depression inventory. Psychological measurements in psychopharmacology: Modern Problems in Pharmacopsychiatry, 7, 151-169. https://doi.org/10.1159/000395074.

Beck, A. T., Epstein, N., Brown, G., \& Steer, R. A. (1988). An inventory for measuring clinical anxiety: psychometric properties. Journal of Consulting Clinical Psychology, 56(6), 893-897. https://doi.org/10. 1037/0022-006X.56.6.893.

Bonomi, A. E., Anderson, M. L., Anderson, R. J., Rivara, F. P., Carrell, D., \& Thompson, R. S. (2009). Medical and psychological diagnoses in women with a history of intimate partner violence. Archives of Internal Medicine, 169, 1692-1697. https://doi.org/10.1001/ archinternmed.2009.292.

Brooks, A. T., Magaña Lòpez, M., Ranucci, A., Krumlauf, M., \& Wallen, G. R. (2017). A qualitative exploration of social support during treatment for severe alcohol use disorder and recovery. Addictive Behaviors Reports, 6, 76-82. https://doi.org/10.1016/j.abrep.2017. 08.002 .

Capaldi, D. M., Knoble, N. B., Shortt, J. W., \& Kim, H. K. (2012). A systematic review of risk factors for intimate partner violence. Partner Abuse, 3(2), 231-280. https://doi.org/10.1891/1946-6560. 3.2.231.

Costa, E. C. V., \& Gomes, S. C. (2018). Social support and self-esteem moderate the relation between intimate partner violence and depression and anxiety symptoms among Portuguese women. Journal of Family Violence, 33(5), 355-368. https://doi.org/10.1007/s10896018-9962-7.
Dandu, A., Bharathi, S., \& Dudala, S. R. (2017). Psychiatric morbidity in spouses of patients with alcohol related disorders. Journal of Family Medicine and Primary Care, 6(2), 305-310. https://doi.org/10. 4103/jfmpc.jfmpc_331_16.

Dawson, D. A., Grant, B. F., Chou, S. P., \& Stinson, F. S. (2007). The impact of partner alcohol problems on women's physical and mental health. Journal of Studies on Alcohol and Drugs, 68(1), 66-75. https://doi.org/10.15288/jsad.2007.68.66.

Djikanovic, B., Jansen, H. A. F. M., \& Otasevic, S. (2010). Factors associated with intimate partner violence against women in Serbia: a cross-sectional study. Journal of Epidemiology and Community Health, 64(8), 728-735. https://doi.org/10.1136/jech.2009.090415.

Djikanovic, B., King, E. J., \& Bjegovic-Mikanovic, V. (2013). Gender differences in health symptoms associated with the exposure to physical violence in family: data from the 2006 national health survey in Serbia. Journal of Family Violence, 28, 753-761. https://doi. org/10.1007/s10896-013-9545-6.

Djikanovic, B., Wong, S. L. F., Simic, S., Marinkovic, J., Van Heel, C., \& Largo-Jansen, A. (2015). Physicians' attitudes and preparedness to deal with intimate partner violence against women in Serbia. Journal of Family Violence, 30, 445-452. https://doi.org/10.1007/ s10896-015-9708-8.

Garcia-Moreno, C., Jansen, H. A., Ellsberg, M., Heise, L., Watts, C. H., \& WHO Multi-country Study on Women's Health and Domestic Violence against Women Study Team. (2006). Prevalence of intimate partner violence: findings from the WHO multi-country study on women's health and domestic violence. Lancet, 368(9543), 1260-1269. https://doi.org/10.1016/S0140-6736(06)69523-8.

Golding, J. M. (1999). Intimate partner violence as a risk factor for mental disorders: a meta-analysis. Journal of Family Violence, 14, 99-132. https://doi.org/10.1023/A:1022079418229.

Greenfield, T. K., Karriker-Jaffe, K. J., Kaplan, L. M., Kerr, W. C., \& Wilsnack, S. C. (2015). Trends in Alcohol's Harms to Others (AHTO) and co-occurrence of family-related AHTO: the four US national alcohol surveys, 2000-2015. Substance Abuse: Research and Treatment, 9(S2), 23-31. https://doi.org/10.4137/SART. S23505.

Heise, L., Ellsberg, M., \& Gottemoeller, M. (1999). Ending violence against women.Population Reports. Series L; No. 11. Baltimore: Johns Hopkins University School of Public Health; Population Information Program.

Huhtanen, P., \& Tigerstedt, C. (2012). Women and young adults suffer most from other people's drinking. Drug and Alcohol Review, 31(7), 841-846. https://doi.org/10.1111/j.1465-3362.2012.00480.x.

Ilic, D. (2014). Results of the Serbian National Health Survey 2013. Belgrade: Ministry of Health and Republic Institute of Public Health "Dr Milan JovanovicBatut."

Indu, P. V., Jinu, C. R., Pallikkal, N. R., Sampathkumar, R., \& Joy, J. (2018). Experience of Domestic Violence and Psychological Morbidity in Spouses of Alcohol-Dependent Males. Indian Journal of Psychological Medicine, 40(4), 322-327. https://doi. org/10.4103/IJPSYM.IJPSYM_38_18.

Karakurt, G., Smith, D., \& Whiting, J. (2014). Impact of intimate partner violence on women's mental health. Journal of Family Violence, 29(7), 693-702. https://doi.org/10.1007/s10896-014-9633-2.

Karriker-Jaffe, K. J., \& Greenfield, T. K. (2014). Gender differences in associations of neighborhood disadvantage with alcohol's harms to others: a cross-sectional study from the USA. Drug and Alcohol Review, 33(3), 296-303. https://doi.org/10.1111/dar.12119.

Karriker-Jaffe, K. J., Greenfield, T. K., \& Kaplan, L. M. (2017). Distress and alcohol-related harms from intimates, friends, and strangers. Journal of Substance Use, 22(4), 434-441. https://doi.org/10. 1080/14659891.2016.1232761.

Kishor, M., Pandit, L. V., \& Raguram, R. (2013). Psychiatric morbidity and marital satisfaction among spouses of men with alcohol 
dependence. Indian Journal of Psychiatry, 55(4), 360-365. https:// doi.org/10.4103/0019-5545.120557.

Kwon, H. J., Ahn, T. K., Lee, J. A., Sunwoo, S., Kim, Y. S., Kim, B. S., et al. (2015). The relationship between a spouse's alcohol use disorder and family communication. Korean Journal of Family Medicine, 36(2), 92-102. https://doi.org/10.4082/kjfm.2015.36.2. 92.

Laslett, A. M., Jiang, H., \& Room, R. (2017). Alcohol's involvement in an array of harms to intimate partners. Drug and Alcohol Review, 36(1), 72-79. https://doi.org/10.1111/dar.12435.

Magán, I., Sanz, J., \& García-Vera, M. P. (2008). Psychometric properties of a Spanish version of the Beck Anxiety Inventory (BAI) in general population. The Spanish Journal of Psychology, 11(2), 626-640. https://doi.org/10.1017/S1138741600004637.

McCann, T. V., Lubman, D. I., Boardman, G., \& Flood, M. (2017). Affected family members' experience of, and coping with, aggression and violence within the context of problematic substance use: a qualitative study. BMC Psychiatry, 17(1). https://doi.org/10.1186/ s12888-017-1374-3

McCann, T. V., Stephenson, J., \& Lubman, D. I. (2019). Affected family member coping with a relative with alcohol and/or other drug misuse: a cross-sectional survey questionnaire. International Journal of Mental Health Nursing, 28(3), 687-696. https://doi.org/10.1111/ inm.12567.

Nayak, M. B., Patterson, D., Wilsnack, S. C., Karriker-Jaffe, K. J., \& Greenfield, T. K. (2019). Alcohol's secondhand harms in the United States: new data on prevalence and risk factors. Journal of Studies on Alcohol and Drugs, 80(3), 273-281. https://doi.org/10. 15288/jsad.2019.80.273.

Nikolic-Ristanovic, V., \& Copic, S. (2016). Dealing with the past in Serbia - achievements in the past 20 years. In M. Fischer \& O. Simic (Eds.), Transitional Justice and Reconciliation: Lessons from the Balkans (pp. 141-168). Abingdon: Routledge.

Orford, J., Padin, M. D. F. R., Canfield, M., Sakiyama, H. M. T., Laranjeira, R., \& Mitsuhiro, S. S. (2019). The burden experienced by Brazilian family members affected by their relatives' alcohol or drug misuse. Drugs: Education, Prevention and Policy, 26(2), 157165. https://doi.org/10.1080/09687637.2017.1393500.

Peacock, A., Leung, J., Larney, S., Colledge, S., Hickman, M., Rehm, J., et al. (2018). Global statistics on alcohol, tobacco and illicit drug use: 2017 status report. Addiction, 113(10), 1905-1926. https://doi. org/10.1111/add.14234.

Quigg, Z., Bellis, M. A., Grey, H., Webster, J., \& Hughes, K. (2019). Alcohol's harms to others in Wales, United Kingdom: nature, magnitude and associations with mental well-being. Addictive Behaviors Reports, 9, 100162. https://doi.org/10.1016/j.abrep. 2019.100162.

Roberts, A., Sharman, S., Landon, J., Cowlishaw, S., Murphy, R., Meleck, S., \& Bowden-Jones, H. (2020). Intimate partner violence in treatment seeking problem gamblers. Journal of Family Violence, 35(1), 65-72. https://doi.org/10.1007/s10896-019-00045-3.

Schuckit, M. A., Smith, T. L., Eng, M. Y., \& Kunovac, J. (2002). Women who marry men with alcohol-use disorders. Alcoholism, Clinical and Experimental Research, 26(9), 1336-1343. https://doi.org/10. 1097/01.ALC.0000029585.63550.33.

Seid, A. K., Grittner, U., Greenfield, T. K., \& Bloomfield, K. (2015). To cause harm and to be harmed by others: new perspectives on alcohol's harms to others. Substance Abuse: Research and Treatment, 9(S2), 13-22. https://doi.org/10.4137/SART.S23506.

Straus, M. A., Hamby, S. L., Boney-McCoy, S., \& Sugarman, D. B. (1996). The Revised Conflict Tactics Scales (CTS2): development and preliminary psychometric data. Journal of Family Issues, 17(3), 283-316. https://doi.org/10.1177/019251396017003001.

UN Women (2020). Issue Brief: Covid -19 and Ending Violence Against Women and Girls. Available at: https://www.unwomen.org/-/media/ headquarters/attachments/sections/library/publications/2020/issuebrief-covid-19-and-ending-violence-against-women-and-girls-en. pdf?la=en\&vs=5006. Accessed 15 May 2020.

Wang, Y. P., \& Gorenstein, C. (2013). Psychometric properties of the Beck Depression Inventory-II: a comprehensive review. Brazilian Journal of Psychiatry, 35(4), 416-431. https://doi.org/10.1590/ 1516-4446-2012-1048.

World Health Organization (2007). WHO Expert committee on problems related to alcohol consumption: Second report. WHO technical report series no.944. Geneva: World Health Organization. ISSN 0512-3054 Available at: https://apps.who.int/iris/bitstream/handle/ 10665/43670/9789241209441_eng.pdf?sequence=1\&isAllowed= y. Accessed 15 May 2020.

World Health Organization (2018). Global status report on alcohol and health 2018. Country Profile Serbia. Geneva: World Health Organization. Available at: https://www.who.int/substance abuse/ publications/global_alcohol_report/profiles/srb.pdf? ua $=1$. Accessed 15 May 2020.

Publisher's Note Springer Nature remains neutral with regard to jurisdictional claims in published maps and institutional affiliations. 